\title{
Microwave and Millimeterwave Spectrum of Chlorofluoroacetylene $(\mathrm{Cl}-\mathrm{C} \equiv \mathrm{C}-\mathrm{F})$
}

\author{
A. Guarnieri and M. Andolfatto \\ Institut für Physikalische Chemie, Abteilung Chemische Physik der Universität Kiel
}

Z. Naturforsch. 36 a, 899-901 (1981); received July 14, 1981

The microwave and millimeterwave spectra of chlorofluoroacetylene ${ }^{35} \mathrm{Cl}-\mathrm{C} \equiv \mathrm{C}-\mathrm{F}$ and ${ }^{37} \mathrm{Cl}-\mathrm{C} \equiv \mathrm{C}-\mathrm{F}$ in natural abundance, have been investigated. The molecule has been found to be linear. The rotational constant, the centrifugal distortion constant $D_{0}$ and the chlorine quadrupole coupling constant have been determined.

Some $r_{0}$-structures have been calculated assuming different values for the $\mathrm{C} \equiv \mathrm{C}$ distance.

\section{Introduction}

During a previous study of the millimeterwave spectrum of Fluoroacetylene [1] it has been found that no investigations have been reported for dihaloacetylenes containing fluorine, although dihaloacetylenes with $\mathrm{Cl}, \mathrm{Br}$ and $\mathrm{Cl}, \mathrm{I}$ have been studied [2]. We report here the results of our investigations on Chlorofluoroacetylene as the first molecule of this serie.

\section{Experimental}

Chlorofluoroacetylene (CFA) was prepared for the first time by Delavarienne and Viehe [3] from 2Fluoro-1, 1-Dichloroethylene [4]. We have used a similar method of synthesis starting from 1,2-Dichloro-1-Fluoroethylene [5] which can be purchased from PCR (Florida, USA). About 1 mole of pure potassium hydroxide $(\mathrm{KOH})$ has been melted in vacuum at about $150^{\circ} \mathrm{C}$ to get it free from oxygen which may react very strongly with CFA and also cause explosion [3].

After this treatment $\mathrm{KOH}$ was allowed to reach room temperature, and then, reduced to very small pieces, has been put into a horizontal glasstube of about $10 \mathrm{~mm}$ diameter and heated up to $110^{\circ} \mathrm{C}$ under a vacuum of $10^{-3}$ Torr for about 24 hours. $1 \mathrm{~g}$ of 1,2-Dichloro-1-Fluoroethylene after vaporization was allowed to pass through the $\mathrm{KOH}$ at $110^{\circ} \mathrm{C}$ very slowly. The reaction products were collected in a trap cooled at liquid air temperature. After a fractionated distillation between $-190^{\circ} \mathrm{C}$ and $-70^{\circ} \mathrm{C}$ we obtained a small amount of CFA which had to be stored at liquid air temperature.

Reprint requests to Prof. Dr. A. Guarnieri, Institut f. Physikal. Chemie, Abt. Chem. Physik, Christian-AlbrechtUniversität Kiel, Olshausenstr. 40-60, 2300 Kiel.
Chlorofluoroacetylene is very reactive and must be handled very carefully. It reacts with air giving explosion. As vapor, at low pressures, it was sufficiently stable to be studied by millimeterwave, Stark or microwave Fourier transform spectroscopy. The pressure in the cell was about $30 \mathrm{mTorr}$ with a substance lifetime of about $15 \mathrm{~min}$.

The millimeterwave spectrum was observed with a conventional spectrometer using Gordy-Type frequency multiplication and OKI-Klystrons as source [6]. Because of the weekness of the absorption lines, source modulation with second derivative presentation was used.

Due to the relative insensitivity to the Stark modulation the low frequency lines have been recorded at first using a $\mathrm{Ku}$-Band-microwave Fourier transform spectrometer described elsewhere [7]. Later, with the purpose of guessing a value for the dipole moment, we performed measurements in the $\mathrm{Ku}$-Band with the Stark modulation spectrometer with fields of $4000 \mathrm{~V} / \mathrm{cm}$ to obtain a sufficiently modulated line. Frequency measurements are believed to be accurate to $10 \mathrm{kHz}$ or $30 \mathrm{kHz}$, for the millimeterwave measurements, depending on the frequency, and to $20 \mathrm{kHz}$ in the case of the $\mathrm{Ku}$ Band measurements.

\section{Spectrum}

The investigation of the prepared compound began with the observation in the millimeterwave range of a sequence of single lines almost equally spaced, confirming the presence of a linear molecule. The obtained rotational constant was in agreement with the one calculated "a priori" within a few MHz. The intensity of the observed lines was comparable with the intensity of the ${ }^{13} \mathrm{C}$ OCS lines. 
A second weeker spectrum with the same characteristics was assigned to the isotopic species with chlorine 37.

No splittings due to the quadrupole coupling effect was visible in this frequency region.

The measurement of the chlorine quadrupole coupling constant $\chi_{z}$ was possible by observing the low frequency lines which appeared as doublets. Tables $1 \mathrm{a}, 1 \mathrm{~b}$ and 2 report the measured and calculated frequencies of the lines for the two isotopic species.

With the measured data the rotational constant $B_{0}$ and the centrifugal distortion constant $D_{0}$ could be well determined for the two isotopic species.

Table 1a. Microwave Spectrum of ${ }^{35} \mathrm{Cl}-\mathrm{C} \equiv \mathrm{C}-\mathrm{F}$. Frequencies of lines are given in $\mathrm{MHz}$.

\begin{tabular}{|c|c|c|c|c|}
\hline \multirow[t]{2}{*}{$J$} & \multirow[t]{2}{*}{$J^{\prime}$} & \multicolumn{2}{|c|}{ Frequencies } & \multirow{2}{*}{$\begin{array}{l}\Delta v \\
(\mathrm{kHz})\end{array}$} \\
\hline & & calculated & measured & \\
\hline 2 & 3 & 13349.050 & $13349.055 *$ & 5 \\
\hline 3 & 4 & 17798.716 & 17798.715 * & -1 \\
\hline 14 & 14 & 62294.052 & 62294.013 & -39 \\
\hline 14 & 15 & 66743.376 & 66743.382 & 6 \\
\hline 18 & 19 & 84540.116 & 84540.17 & 53 \\
\hline 10 & 20 & 88989.145 & 88989.14 & -5 \\
\hline 20 & 21 & 93438.105 & 93438.04 & -65 \\
\hline 21 & 22 & 97886.992 & 97886.98 & -12 \\
\hline 22 & 23 & 102335.803 & 102335.78 & -22 \\
\hline 23 & 24 & 106784.533 & 106784.57 & 36 \\
\hline 24 & 25 & 111233.181 & 111233.14 & -41 \\
\hline 30 & 31 & 137923.125 & 137923.26 & 134 \\
\hline 31 & 32 & 142371.093 & 142371.06 & -33 \\
\hline 32 & 33 & 146818.950 & 146818.95 & -0 \\
\hline 38 & 39 & 173503.569 & 173503.57 & 1 \\
\hline 39 & 40 & 177950.552 & 177950.52 & -32 \\
\hline
\end{tabular}

* Corrected for the quadrupole coupling splitting.

Table $1 \mathrm{~b}$. Microwave Spectrum of ${ }^{37} \mathrm{Cl}-\mathrm{C} \equiv \mathrm{C}-\mathrm{F}$. Frequencies of lines are given in $\mathrm{MHz}$.

\begin{tabular}{rrrrr}
\hline$J$ & $J^{\prime}$ & \multicolumn{2}{c}{ Frequencies } & \multicolumn{1}{l}{$\Delta v$} \\
\cline { 3 - 4 } & & calculated & measured & $(\mathrm{kHz})$ \\
\hline 2 & 3 & $\mathbf{1 3 0 2 9 . 9 7 1}$ & $\mathbf{1 3 0 2 9 . 9 7 3 *}$ & $\mathbf{2}$ \\
3 & 4 & $\mathbf{1 7 3 7 3 . 2 7 9}$ & $\mathbf{1 7 3 7 3 . 2 8 2} *$ & 3 \\
13 & 14 & $\mathbf{6 0 8 0 5 . 0 8 7}$ & $\mathbf{6 0 8 0 5 . 0 7 0}$ & $-\mathbf{1 7}$ \\
14 & 15 & $\mathbf{6 5 1 4 8 . 0 6 8}$ & $\mathbf{6 5 1 4 8 . 0 9 5}$ & 27 \\
20 & 21 & $\mathbf{9 1 2 0 4 . 7 9 6}$ & $\mathbf{9 1 2 0 4 . 7 6}$ & -36 \\
22 & 23 & $\mathbf{9 9 8 8 9 . 8 5 3}$ & 99889.85 & -3 \\
23 & 24 & 104232.269 & 104232.32 & 51 \\
24 & 25 & 108574.605 & 108574.60 & -5 \\
32 & 33 & $\mathbf{1 4 3 3 1 0 . 0 4 5}$ & $\mathbf{1 4 3 3 1 0 . 0 4}$ & -5 \\
33 & 34 & $\mathbf{1 4 7 6 5 1 . 5 1 9}$ & $\mathbf{1 4 7 6 5 1 . 4 9}$ & -29 \\
39 & 40 & $\mathbf{1 7 3 6 9 7 . 8 8 7}$ & $\mathbf{1 7 3 6 9 7 . 9 3}$ & $\mathbf{4 3}$ \\
$\mathbf{4 0}$ & $\mathbf{4 1}$ & $\mathbf{1 7 8 0 3 8 . 5 0 5}$ & $\mathbf{1 7 8 0 3 8 . 4 8}$ & -25 \\
\hline
\end{tabular}

* Corrected for the quadrupole coupling splitting.
Table 2. Lines split by quadrupole coupling effect of chlorine nucleus. - Frequencies of Lines are in MHz.

\begin{tabular}{|c|c|c|c|c|c|c|}
\hline \multirow[t]{2}{*}{$J$} & \multirow[t]{2}{*}{$J^{\prime}$} & \multirow[t]{2}{*}{$F$} & \multirow[t]{2}{*}{$F^{\prime}$} & \multicolumn{2}{|c|}{ Frequencies } & \multirow{2}{*}{$\begin{array}{l}\Delta v \\
(\mathrm{kHz})\end{array}$} \\
\hline & & & & Measured & Calculated & \\
\hline \multicolumn{7}{|c|}{${ }^{35} \mathbf{C l}-\mathbf{C} \equiv \mathbf{C}-\mathbf{F}$} \\
\hline \multirow{2}{*}{2} & \multirow{2}{*}{3} & $\left\{\begin{array}{l}3 / 2 \\
1 / 2\end{array}\right.$ & $\begin{array}{l}5 / 2 \\
3 / 2\end{array}$ & 13344.910 & 13344.905 & 5 \\
\hline & & $\begin{array}{l}9 / 2 \\
7 / 2\end{array}$ & $\begin{array}{l}7 / 2 \\
5 / 2\end{array}$ & 13350.038 & 13350.043 & 5 \\
\hline \multirow{2}{*}{3} & \multirow{2}{*}{4} & $\left\{\begin{array}{l}5 / 2 \\
3 / 2\end{array}\right.$ & $\begin{array}{l}7 / 2 \\
5 / 2\end{array}$ & 17796.931 & 17796.932 & -1 \\
\hline & & $\begin{array}{l}9 / 2 \\
7 / 2\end{array}$ & $\begin{array}{r}11 / 2 \\
9 / 2\end{array}$ & 17799.347 & 17799.348 & -1 \\
\hline \multicolumn{7}{|c|}{${ }^{37} \mathbf{C l}-\mathbf{C} \equiv \mathbf{C}-\mathbf{F}$} \\
\hline \multirow{2}{*}{2} & \multirow{2}{*}{3} & $\int \begin{array}{l}3 / 2 \\
1 / 2\end{array}$ & $\begin{array}{l}5 / 2 \\
3 / 2\end{array}$ & 13026.694 & 13026.692 & 2 \\
\hline & & $\left\{\begin{array}{l}7 / 2 \\
5 / 2\end{array}\right.$ & $\begin{array}{l}9 / 2 \\
7 / 2\end{array}$ & 13030.752 & 13030.753 & -1 \\
\hline \multirow{2}{*}{3} & \multirow{2}{*}{4} & $\left\{\begin{array}{l}5 / 2 \\
3 / 2\end{array}\right.$ & $\begin{array}{l}7 / 2 \\
5 / 2\end{array}$ & 17371.875 & 17371.872 & +3 \\
\hline & & $\begin{array}{l}9 / 2 \\
7 / 2\end{array}$ & $\begin{array}{r}11 / 2 \\
9 / 2\end{array}$ & 17373.780 & 17373.777 & 3 \\
\hline
\end{tabular}

Table 3. Rotational constant, centrifugal distortion constant and quadrupole coupling constant for ${ }^{35} \mathrm{Cl}-\mathrm{C} \equiv \mathrm{C}-\mathrm{F}$ and ${ }^{37} \mathrm{Cl}-\mathrm{C} \equiv \mathrm{C}-\mathrm{F}$ in the ground state. Errors are three times the standard errors of the fitting procedure. - All Data are in MHz.

\begin{tabular}{lcc}
\hline $35 \mathrm{Cl}-\mathrm{C} \equiv \mathbf{C}-\mathrm{F}$ & \\
$B_{0}$ & 2224.8442 & \pm 0.0012 \\
$D_{0}$ & $1.445 \cdot 10^{-4}$ & $\pm 0.6 \cdot 10^{-6}$ \\
$\chi_{z z}$ & 83.0 & \pm 0.1 \\
${ }^{37} \mathrm{Cl}-\mathrm{C} \equiv \mathrm{C}-\mathrm{F}$ & \\
$B_{0}$ & 2171.6642 & \pm 0.0012 \\
$D_{0}$ & $1.377 \cdot 10^{-4}$ & $\pm 0.6 \cdot 10^{-6}$ \\
$\chi_{z z}$ & 65.6 & \pm 0.1 \\
\hline
\end{tabular}

All the determined molecular parameters are given in Table 3.

\section{Structure}

As only two isotopic species have been studied, an approach to the $r_{0}$-structure of $\mathrm{F}-\mathrm{C} \equiv \mathrm{C}-\mathrm{Cl}$ involves necessarily a comparison with the structures of other mono- or bihalogenated acetylenes which have been already studied by microwave spectroscopy. We listed the interesting data for these molecules in Table 4. As it can be seen the $\mathrm{C} \equiv \mathrm{C}$ triple bond distance has been found to lie between 1.200 and 1.209 $\AA$. Assuming four values for the $\mathrm{C} \equiv \mathrm{C}$ distances in this range it is possible to fit the $\mathrm{C}-\mathrm{F}$ 
Table 4. Structure data for monohalo- and bihaloacetylenes as studied by Microwave Spectroscopy. Bond lengths are given in $\AA$.

\begin{tabular}{|c|}
\hline $\mathrm{H}_{1.053} \mathrm{C}_{1.198} \mathrm{C}_{1.279} \mathrm{~F}$ a) \\
\hline $\mathrm{H}_{1.055} \mathrm{C}_{1.203} \mathrm{C}_{1.637} \mathrm{Cl}$ b) \\
\hline 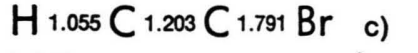 \\
\hline $\mathrm{NC}_{1.369} \mathrm{C}_{1.209} \mathrm{C}_{1.625} \mathrm{Cl}$ \\
\hline $\mathrm{NC}_{1.369} \mathrm{C}_{1.204} \mathrm{C}_{1.786 \mathrm{Br}}$ \\
\hline $\mathrm{Br}{ }_{1.790} \mathrm{C}_{1.209} \mathrm{C}_{1.628 \mathrm{Cl}}$ \\
\hline${ }_{1.989} \mathrm{C}_{1.209} \mathrm{C}_{1.627} \mathrm{Cl}$ \\
\hline
\end{tabular}

a J. K. Tyler and J. Sheridan, Trans. Faraday Soc. 59, 2661 (1963).

b H. Jones, M. Takami, and J. Sheridan, Z. Naturforsch. $33 \mathrm{a}, 156$ (1978).

c H. Jones, T. Sheridan, and O. C. Stiefvater, Z. Naturforsch. 32a, 866 (1977).

d T. Bjorvatten, J. Mol. Struc. 20, 75 (1974).

e A. Bjørseth, E. Kloster-Jensen, K. M. Marstokk, and H. Møllendal, J. Mol. Struc. 6, 181 (1970).

Table 5. $r_{0}$-Structure data in $\AA$ for $\mathrm{Cl}-\mathrm{C} \equiv \mathrm{C}-\mathrm{F} . \mathrm{C} \equiv \mathrm{C}$ Distances are assumed fixed to the values in parenthesis.

\begin{tabular}{lllll}
\hline $\mathrm{C} \equiv \mathrm{C}$ & $\mathrm{C}-\mathrm{F}$ & $\mathrm{C}-\mathrm{Cl}$ & \multicolumn{3}{l}{$B_{0}$ (calc) $\mathrm{MHz}$} \\
\cline { 3 - 5 } & & & ${ }^{35} \mathrm{Cl}-\mathrm{C} \equiv \mathrm{C}-\mathrm{F}$ & ${ }^{37} \mathrm{Cl}-\mathrm{C} \equiv \mathrm{C}-\mathrm{F}$ \\
\hline$(1.200)$ & 1.278 & 1.636 & 2224.073 & 2170.910 \\
$(1.203)$ & 1.276 & 1.634 & 2224.769 & 2171.512 \\
$(1.206)$ & 1.274 & 1.633 & 2224.126 & 2170.976 \\
$(1.209)$ & 1.270 & 1.632 & 2225.374 & 2172.185 \\
\hline
\end{tabular}

Conversion factor $505.531 \mathrm{GHz} / \mathrm{AMU} \cdot \mathrm{A}^{2}$.

and $\mathrm{C}-\mathrm{Cl}$ distances on the basis of the rotational constants obtained from the spectra.

The four sets of obtained parameters are listed in Table 5.

\section{Quadrupole Coupling Constant}

The quadrupole coupling constant of $-83.0 \mathrm{MHz}$ for ${ }^{35} \mathrm{Cl}-\mathrm{C} \equiv \mathrm{C}-\mathrm{F}\left(-65.6 \mathrm{MHz}\right.$ for $\left.{ }^{37} \mathrm{Cl}-\mathrm{C} \equiv \mathrm{C}-\mathrm{F}\right)$

[1] F. Rohwer, Thesys Univ. of Kiel, to be published.

[2] A. Bjørseth, et al., J. Mol. Structure 6, 181 (1970).

[3] S. Y. Delavarienne and H. G. Viehe, Chem. Ber. 103, 1198 (1970)

[4] A. L. Henne and E. C. Ladd, J. Amer. Chem. Soc. 58, 402 (1936).

[5] 1,2-Dichloro-1-Fluoroethylene. - Art. Nr. 12 220-0 by PCR, Florida, USA.

[6] M. Suzuki, A. Guarnieri, and H. Dreizler, Z. Naturforsch. 31 a, 1181 (1976). agrees with the value of $-83.4 \mathrm{MHz}$ found for ${ }^{35} \mathrm{Cl}-\mathrm{CN}[8]\left(-65.8 \mathrm{MHz}\right.$ for $\left.{ }^{37} \mathrm{Cl}-\mathrm{CN}\right)$ and with the values of $-79.7 \mathrm{MHz}$ and $-74 \pm 4 \mathrm{MHz}$ found, respectively, for ${ }^{35} \mathrm{Cl}-\mathrm{C} \equiv \mathrm{C}-\mathrm{H}$ [9] $(-62.7 \mathrm{MHz}$ for $\left.{ }^{37} \mathrm{Cl}-\mathrm{C} \equiv \mathrm{C}-\mathrm{H}\right)$ and ${ }^{35} \mathrm{Cl}-\mathrm{C} \equiv \mathrm{C}-\mathrm{CN} \quad[10]$ $\left(-62 \pm 3 \mathrm{MHz}\right.$ for $\left.{ }^{37} \mathrm{Cl}-\mathrm{C} \equiv \mathrm{C}-\mathrm{CN}\right)$. A comparison of these values indicates a large similarity in the electric field gradient of the electrons on the chlorine nucleus.

A strong tendency for conjugation of the C-Halogen bond with the adjacent triple bond $[11,12]$ is found for all these substances with calculated $\pi$ character percentage of $22-28 \%$. Following the well known formulas given in [12] a percentage of $\pi$-character in the $\mathrm{C}-\mathrm{Cl}$ bond of $20 \%$ is found in $\mathrm{F}-\mathrm{C} \equiv \mathrm{C}-\mathrm{Cl}$ using for the ionic character of the $\sigma$-bond a value of 0.15 .

\section{Dipole Moment}

Due to the complicated hyperfine quadrupole coupling structure and to the impossibility to reach fields higher than $4000 \mathrm{~V} / \mathrm{cm}$ with the conventional Stark spectrometer, a rough value for the electric dipole moment was guessed observing the sensitivity to the modulation of the strongest of the two quadrupole satellites of the $J=2-2$ line at 13350 $\mathrm{MHz}$. A dipole moment of about $0.25 \pm 0.1 \mathrm{D}$ was found.

\section{Acknowledgements}

We are grateful to Dipl.-Chem. E. Fliege, to Dipl.Phys. G. Bestmann and to Prof. Dr. H. Dreizler for making available measurements with the $\mathrm{Ku}$-Bandmicrowave Fourier transform spectrometer. Thanks are due to the other members of the Laboratory for helpful discussions and to the Deutsche Forschungsgemeinschaft for research funds.

Calculations have been made with the PDP 10 of the Rechenzentrum der Universität Kiel.

[7] G. Bestmann, H. Dreizler, H. Mäder, and U. Andresen, Z. Naturforsch. 35 a, 392 (1980).

[8] W. J. Lafferty, D. R. Lide, and R. A. Toth, J. Chem. Phys. 43, 2063 (1965).

[9] A. A. Westenberg, J. H. Goldstein, and E. B. Wilson, J. Chem. Phys. 17, 1319 (1949).

[10] T. Bjorvatten, J. Mol. Struc. 20, 75 (1974).

[11] W. Gordy, Disc. Faraday Soc. 19, 9 (1955).

[12] W. Gordy and R. L. Cook, Microwave Molecular Spectra Interscience Publ. New York 1970, p. $587 \mathrm{ff}$. 